\title{
Oxidative ring cleavage of 2,3-dihydrophthalazine-1,4-dione in aqueous and non-aqueous solutions: Electrochemical and kinetic studies
}

\author{
D NEMATOLLAHI ${ }^{\mathrm{a}, *}$, S S HOSSEINY DAVARANI ${ }^{\mathrm{b}}, \mathrm{P}^{\mathrm{M}}$ MIRAHMADPOUR $^{\mathrm{c}}$ and \\ F VARMAGHANI ${ }^{\mathrm{a}}$ \\ ${ }^{a}$ Faculty of Chemistry, Bu-Ali Sina University, Hamedan, Iran, 65178-38683 \\ ${ }^{b}$ Department of Chemistry, Faculty of Science, University of Shahid Beheshti, Tehran 19835389, Iran \\ ${ }^{c}$ Department of Chemistry, Shahre-Qods Branch, Islamic Azad University, Tehran, Iran \\ e-mail: dnematollahi@yahoo.com
}

MS received 10 February 2014; revised 7 June 2014; accepted 11 June 2014

\begin{abstract}
Electrochemical oxidation of 2,3-dihydrophthalazine-1,4-dione (DHP) has been investigated in aqueous and some amphiprotic and aprotic non-aqueous solvents by cyclic voltammetric and controlledpotential coulometric techniques. Our data shows that electrochemically generated phthalazine-1,4-dione (PTD) in water and amphiprotic non-aqueous solvents participates in an oxidative ring cleavage (ORC) reaction to form phthalic acid. The rate of this reaction is dependent. On autoprotolysis constant $\left(K_{\mathrm{SH}}\right)$ and basicity of the solvent. Therefore, in the aprotic non-aqueous solvents such as acetonitrile and DMSO, the rate of ORC is too slow to be observed on the time-scale of cyclic voltammetry.
\end{abstract}

Keywords. 2,3-Dihydrophthalazine-1,4-dione; oxidative ring cleavage; aprotic and amphiprotic solvents; cyclic voltammetry.

\section{Introduction}

2,3-Dihydrophthalazine-1,4-diones (phthalylhydrazides) (DHP) are commonly used as intermediates for pharmaceuticals and synthesis of organic compounds and drug molecules. ${ }^{1}$ Its unique biological activities serving as anti-convulsant, ${ }^{2}$ anti-microbial, ${ }^{3}$ antifungal, ${ }^{4}$ vasorelaxant,${ }^{5}$ anti-HIV,${ }^{6}$ anti-cancer activity, ${ }^{7}$ PDE3/PDE4 inhibitory agents, ${ }^{8}$ anti-asthamatic, ${ }^{9}$ leishmanicidal ${ }^{10}$ and anti-diabetic have made synthetic studies of the phthalazine ring system attractive over the years. The chemical oxidation of 2,3-dihydrophthalazine1,4-dione and its derivatives has previously been carried out both in water and organic solvents for the synthesis of some organic compounds via the nucleophilic addition or Diels-Alder reactions. ${ }^{11-15}$ The results of these studies show that the generated diazanaphthoquinone from the oxidation of 2,3-dihydrophthalazine1,4-dione is unstable. In addition, the electrochemical oxidation of 1,2-dihydropyridazine-3,6-dione has recently been studied and shown that electrochemically generated diazaquinone is very reactive. ${ }^{16}$ Furthermore, we recently studied the electrochemical oxidation of 2,3-dihydrophthalazine-1,4-dione in the presence and

*For correspondence absence of indole derivatives. ${ }^{17}$ Cyclic voltammograms of this compound in the absence of indole show one anodic $\left(\mathrm{A}_{1}\right)$ peak and its corresponding cathodic peak $\left(\mathrm{C}_{1}\right)$. These peaks correspond to the transformation of 2,3-dihydrophthalazine-1,4-dione (DHP) to phthalazine-1,4-dione (diazanaphthoquinone) (PTD) and vice versa, within a quasi-reversible two-electron process with a peak current ratio $\left(I_{\mathrm{pCl}} / I_{\mathrm{pA} 1}\right)$ less than unity. ${ }^{17}$ This confirms the instability of the generated PTD. The higher reactivity or instability of PTD can be due to the simultaneous presence of both carbonyl and azo moieties. On the other hand, the instability of PTD depends on the experimental conditions, and so the optimization of experimental parameters seems to be important. It also seems that the kinetic evaluation of the stability of PTD is interesting for all workers who deal with these compounds.

The importance of DHP on the one hand and the lack of electrochemical data on the other hand, prompted us to investigate the electrochemical oxidation of DHP in aqueous and a few non-aqueous solvents using cyclic voltammetry. Our results show that the electrogenerated PTD undergoes oxidative ring cleavage and converts to the phthalic acid. In this direction, we have also investigated the electrochemical oxidation of DHP in a few non-aqueous solvents to increase available data on oxidative ring cleavage of DHP. 


\section{Experimental}

\subsection{Apparatus and reagents}

Cyclic voltammetry and preparative electrolysis were carried out using a $\mu$ Autolab potentiostat/galvanostat type III. The working electrode used in the voltammetry experiment was a glassy carbon disc $(1.8 \mathrm{~mm}$ diameter) and platinum wire $(2 \mathrm{~mm}$ diameter and $1.6 \mathrm{~cm}$ length) was used as the counter electrode. The working electrode potentials were measured versus the $\mathrm{Ag} / \mathrm{AgCl}$ $(\mathrm{KCl}, 3 \mathrm{M})$ as a reference electrode (all electrodes were obtained from Metrohm). The working electrode used in controlled-potential coulometry and macroscale electrolysis was an assembly of three carbon rods $(8 \mathrm{~mm}$ diameter and $6 \mathrm{~cm}$ length). The $\mathrm{pH}$ was measured using a Metrohm $\mathrm{pH}$ meter 744 with a combined glass electrode.

2,3-Dihydrophthalazine-1,4-dione and other chemicals were obtained from Sigma-Aldrich; these chemicals were used without further purification. The solvents were kept over $0.3 \mathrm{~nm}$ molecular sieves for $48 \mathrm{~h}$ prior to use and then were used without further purification.

\section{Results and Discussion}

\subsection{Electrochemical studies in water/acetonitrile mixture}

The cyclic voltammograms of 2,3-dihydrophthalazine1,4-dione (DHP) $(1.0 \mathrm{mM})$ in water (phosphate buffer, $c=0.2 \mathrm{M}, \mathrm{pH}=2.5) /$ acetonitrile mixture $(80 / 20, \mathrm{v} / \mathrm{v})$ at different potential scan rates are shown in figure 1 . In the low scan rate $(50 \mathrm{mV} / \mathrm{s}$ ) (curve a), the cyclic voltammogram exhibits the feature of an irreversible electron-transfer process with an anodic peak $\left(\mathrm{A}_{1}\right)$ at $0.85 \mathrm{~V}$ versus $\mathrm{Ag} / \mathrm{AgCl}$ which corresponds to the transformation of DHP to phthalazine-1,4-dione (PTD). The subsequent chemical reaction is supported by the lack of corresponding cathodic peak $\mathrm{C}_{1}$ during the reverse scan in low scan rate. The height of $I_{\mathrm{pC} 1}$ increases with the scan rate. This could be indicative of the fact that electrochemically generated PTD in the surface of electrode via a fast chemical reaction is converted to an electro-inactive compound.

The electrochemical oxidation of DHP in water (buffered with various pHs)/acetonitrile $(80 / 20, \mathrm{v} / \mathrm{v}$ ) mixture has been studied using cyclic voltammetry. It was found that by increasing $\mathrm{pH}$, the potential of peak $\mathrm{A}_{1}\left(E_{\mathrm{pA} 1}\right)$ is shifted to the negative potentials. This is predictable due to the participation of protons in the

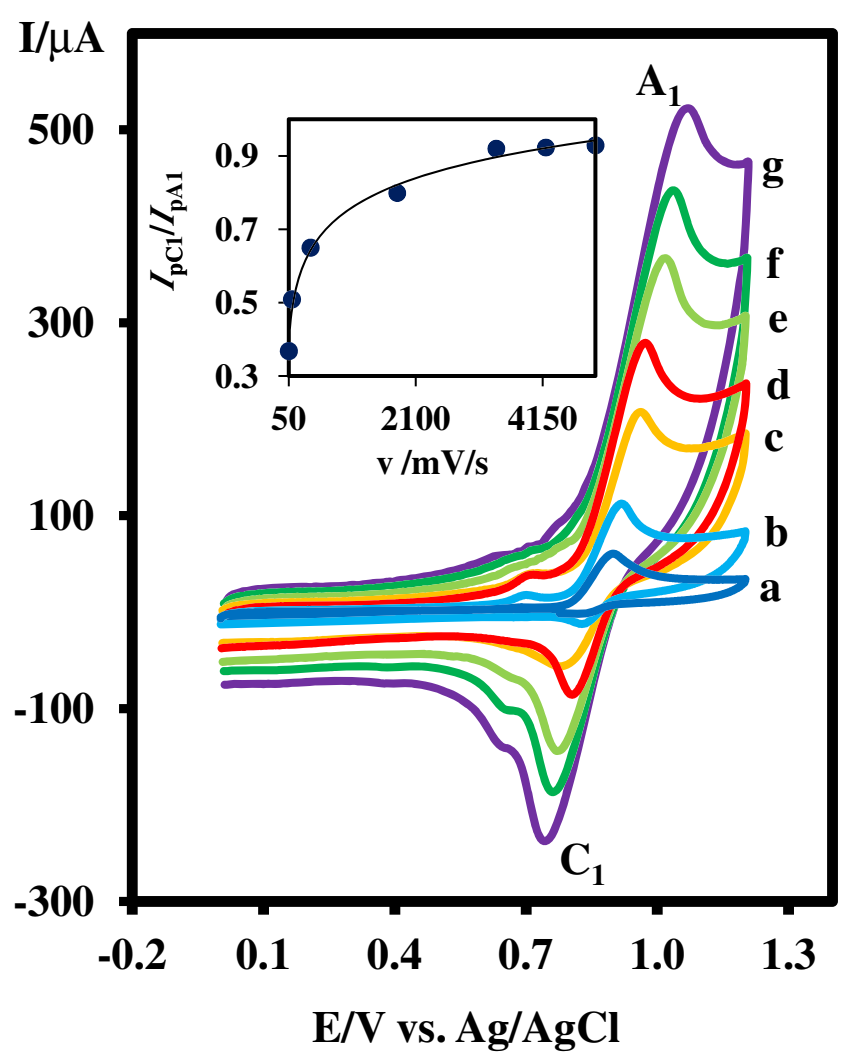

Figure 1. Typical cyclic voltammograms of DHP $(1.0 \mathrm{mM})$ at various scan rates. Scan rates from a to $\mathrm{g}$ are: $50,100,400,1800,3400,4200$ and $5000 \mathrm{mV} \mathrm{s}^{-1}$, respectively, at a glassy carbon electrode in water (phosphate buffer, $c=0.2 \mathrm{M}, \mathrm{pH}=2.5) /$ acetonitrile mixture (80/20, $\mathrm{v} / \mathrm{v}) . T=25 \pm 1{ }^{\circ} \mathrm{C}$. Inset: Variation of peak current ratios $\left(I_{\mathrm{pCl}} / I_{\mathrm{pA} 1}\right)$ versus scan rate.

oxidation reaction of DHP. The anodic peak potential $\left(E_{\mathrm{pA} 1}\right)$, is given by:

$$
E_{\mathrm{pA}}^{\prime}=E_{\mathrm{pA}(\mathrm{pH}=0)}-(2.303 m R T / 2 F) \mathrm{pH}
$$

where $m$ is the number of protons involved in the reaction and $E_{\mathrm{pA}(\mathrm{pH}=0)}$ is the anodic peak potential at $\mathrm{pH}=$

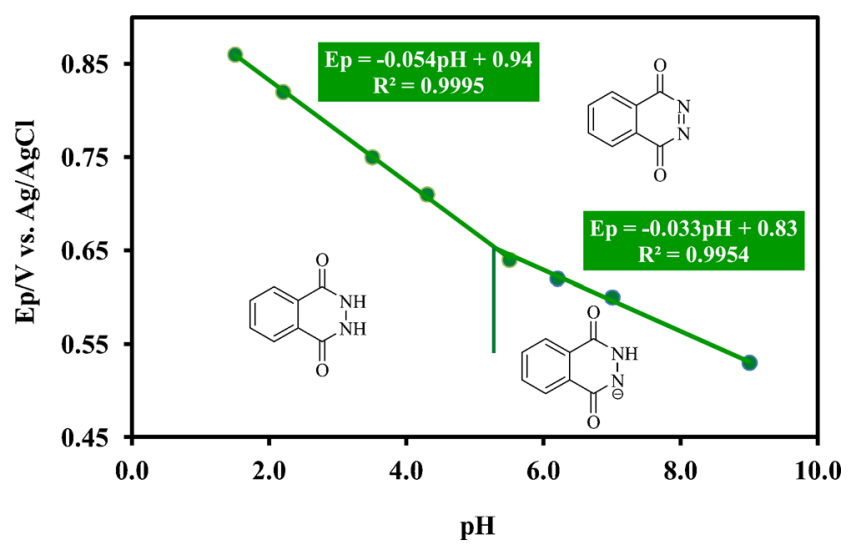

Figure 2. Variation of oxidation potential $\left(E_{\mathrm{pA} 1}\right)$ of $\mathbf{D H P}$ as a function of $\mathrm{pH}$. 


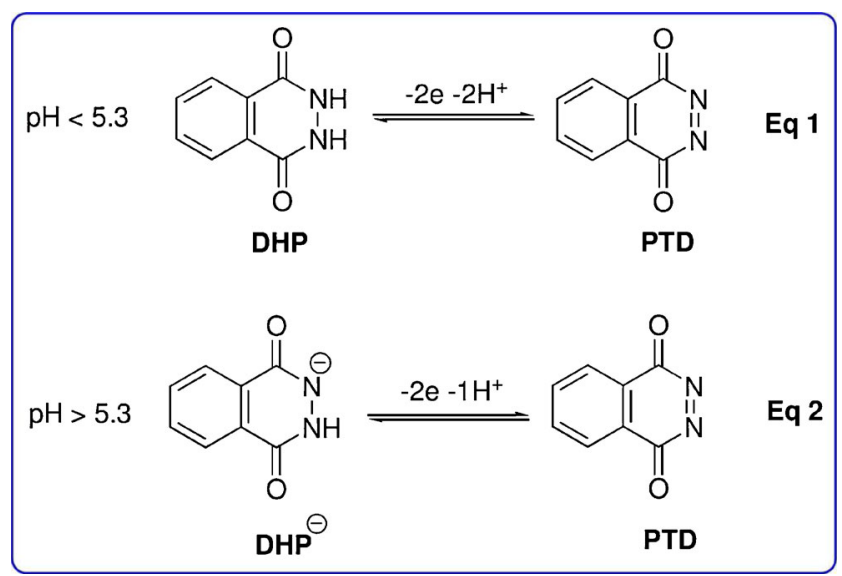

Scheme 1. Electrochemical oxidation of 2,3-dihydrophthalazine-1,4-dione (DHP) at various pHs.

$0.0, R, T$, and $F$ have their usual meanings. An $E-\mathrm{pH}$ diagram is constructed for oxidation of DHP by plotting the $E_{\mathrm{pA}}$ values as a function of $\mathrm{pH}$ (figure 2). The $E_{\mathrm{pA}}-$ $\mathrm{pH}$ diagram comprise two linear segments with different equations and slopes around $\mathrm{pH}=5.3$. The first segment $(\mathrm{pHs}<5.3)$ represents a line with a slope of $54 \mathrm{mV} / \mathrm{pH}$ and intercept of $0.94 \mathrm{~V}$ vs. $\mathrm{Ag} / \mathrm{AgCl}$ and the second segment $(\mathrm{pHs}>5.3)$ shows a line with a slope of $33 \mathrm{mV} / \mathrm{pH}$ and intercept of $0.83 \mathrm{~V}$ vs. $\mathrm{Ag} / \mathrm{AgCl}$. On the basis of the above mentioned slope, it can be concluded that the electrode surface reaction occurring at the $\mathrm{pH}$ $<5.3$, corresponds to the two-electron, two-proton process (scheme 1, Eq. 1). Whereas, the electrode surface reaction at $\mathrm{pH}>5.3$ is a two-electron, one-proton process involving the oxidation of 'anionic form' of DHP $\left(\mathbf{D H P}^{-}\right)$to the corresponding PTD (scheme 1, Eq. 2). Also, the $\mathrm{pK}_{\mathrm{a}}$ of acid/base equilibrium shown in scheme 2 is 5.3 . The hydrogen attached to nitrogen in DHP is more acidic than 1,2-dihydropyridazine-3,6dione $\left(\mathrm{pK}_{\mathrm{a}}=5.58\right),{ }^{16}$ due to the presence of electron withdrawing phenyl group.

Controlled-potential coulometry was carried out in water (phosphate buffer, $c=0.2 \mathrm{M}, \mathrm{pH}=$ 2.5)/acetonitrile mixture $(80 / 20, \mathrm{v} / \mathrm{v})$ containing of DHP $(0.25 \mathrm{mmol})$ at $E_{\mathrm{pA} 1}(0.85 \mathrm{~V}$ versus $\mathrm{Ag} / \mathrm{AgCl})$. Cyclic voltammetric analysis carried out during the

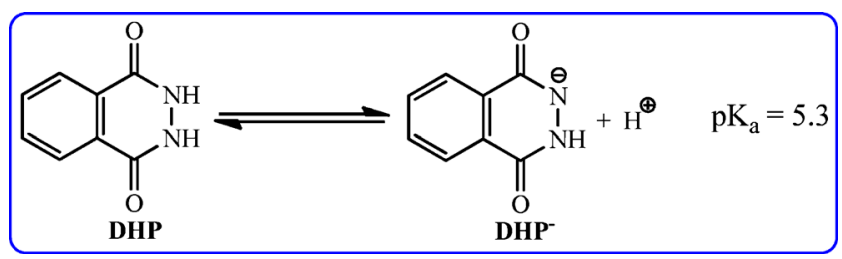

Scheme 2. Acid/base equilibrium of 2,3-dihydrophthalazine1,4-dione (DHP). electrolysis shows the decrease in the peak $A_{1}$. This peak disappears when the charge consumption becomes about $4 \mathrm{e}^{-}$per molecule of DHP. Diagnostic criteria of cyclic voltammetry, consumption of four electrons<smiles>O=C1N=NC(=O)c2ccccc21</smiles>

$$
2 \mathrm{H}_{2} \mathrm{O} \rightleftharpoons \mathrm{H}_{3} \mathrm{O}^{+}+\mathrm{OH}^{-} \quad \mathrm{p} K_{\mathrm{w}}=14.0
$$<smiles>O=C1N=NC(=O)C(CC2CC2)C1=O</smiles><smiles>O=C1N=NC(O)(COC2(O)CCCCC2)c2ccccc21</smiles>

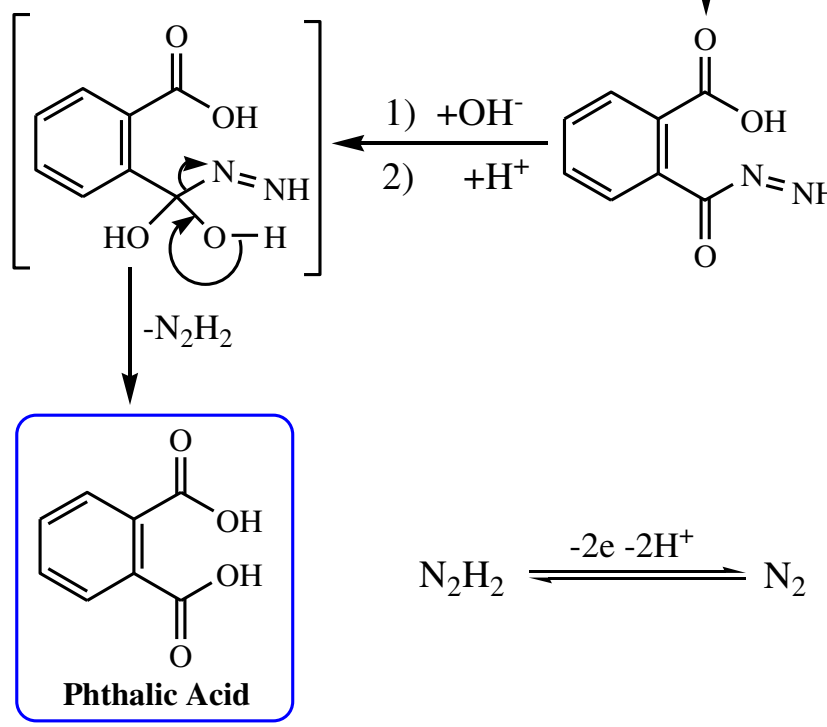

The overall reaction:<smiles>O=c1[nH][nH]c(=O)c2ccccc12</smiles>

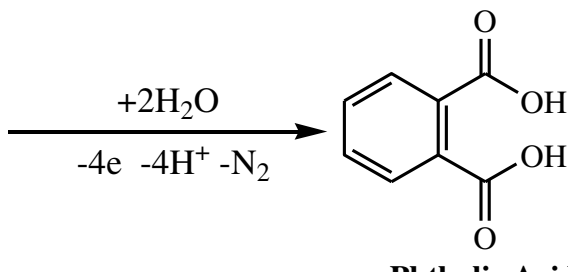

Scheme 3. Proposed mechanism for the electrochemical oxidation of 2,3-dihydrophthalazine-1,4-dione (DHP). 
Table 1. Autoprotolysis constant and basicity of the studied solvents. ${ }^{20}$

\begin{tabular}{|c|c|c|c|c|c|c|}
\hline Solvent & Water & Acetic acid & Methanol & Ethanol & Acetonitrile & DMSO \\
\hline $\mathrm{p} K_{\mathrm{SH}}$ & 14.0 & 14.45 & 17.2 & 19.1 & 33.3 & 33.3 \\
\hline Basicity ${ }^{a}$ & & \pm & + & + & - & ++ \\
\hline
\end{tabular}

${ }^{a}$ The symbol + is for the case comparable with water, ++ for the case much stronger than water, \pm for the case somewhat weaker than water, and - for the case much weaker than water.

per molecule of DHP, and the mass spectrum of isolated product $(m / z=166)$ indicate oxidative ring cleavage of DHP. The electrochemically generated
PTD is a reactive electrophile and nucleophilic addition of hydroxide ion (or water) to carbonyl group led to oxidative ring cleavage (scheme 3 ).
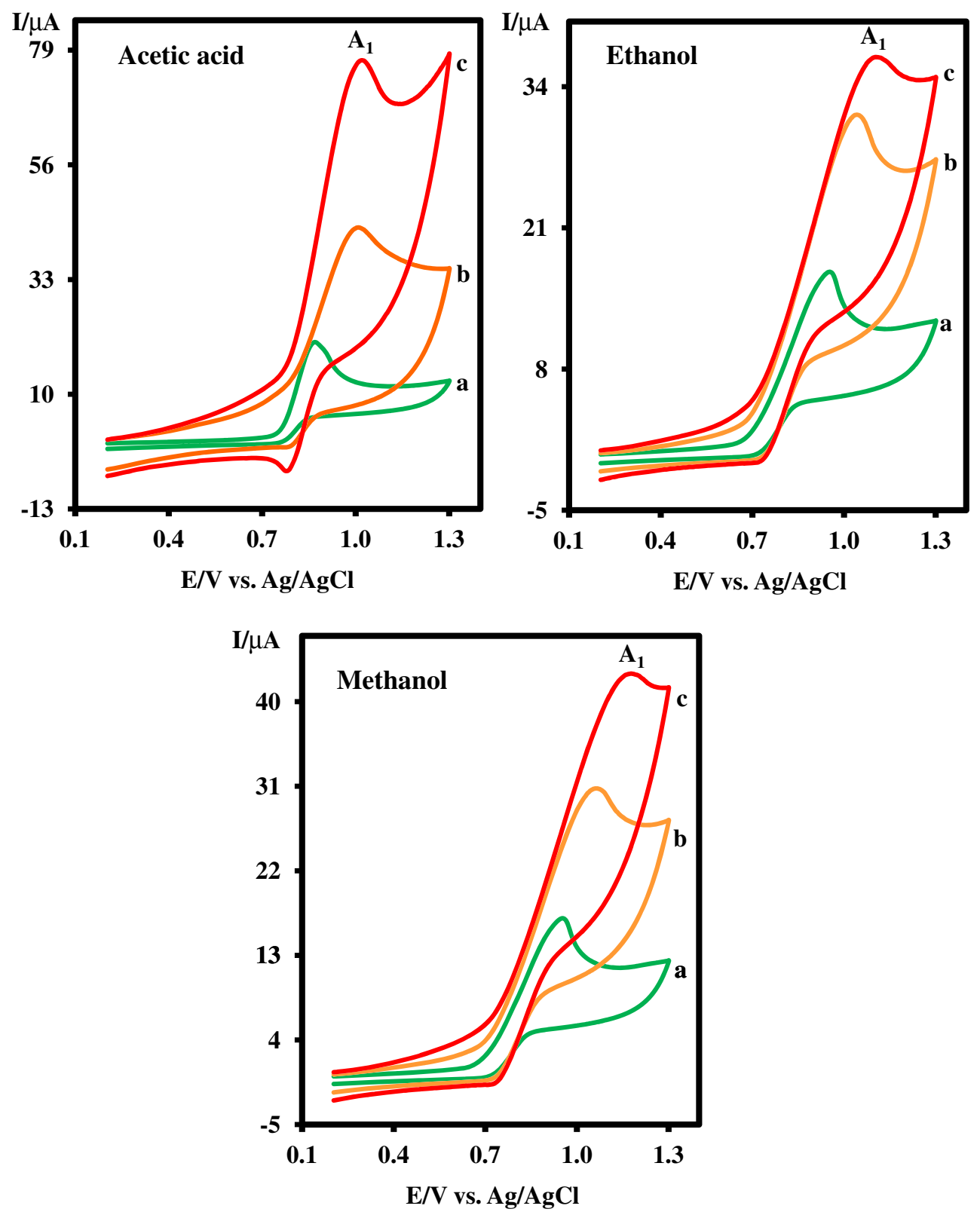

Figure 3. Cyclic voltammograms of DHP $(1.0 \mathrm{mM})$ at various scan rates in the presence of tetrabutylammonium perchlorate $(0.1 \mathrm{M})$, in methanol, ethanol and acetic acid, at a glassy carbon electrode. Scan rates from a to $\mathrm{d}$ are 10,50 and $100 \mathrm{mV} / \mathrm{s} . T=25 \pm 1^{\circ} \mathrm{C}$. 

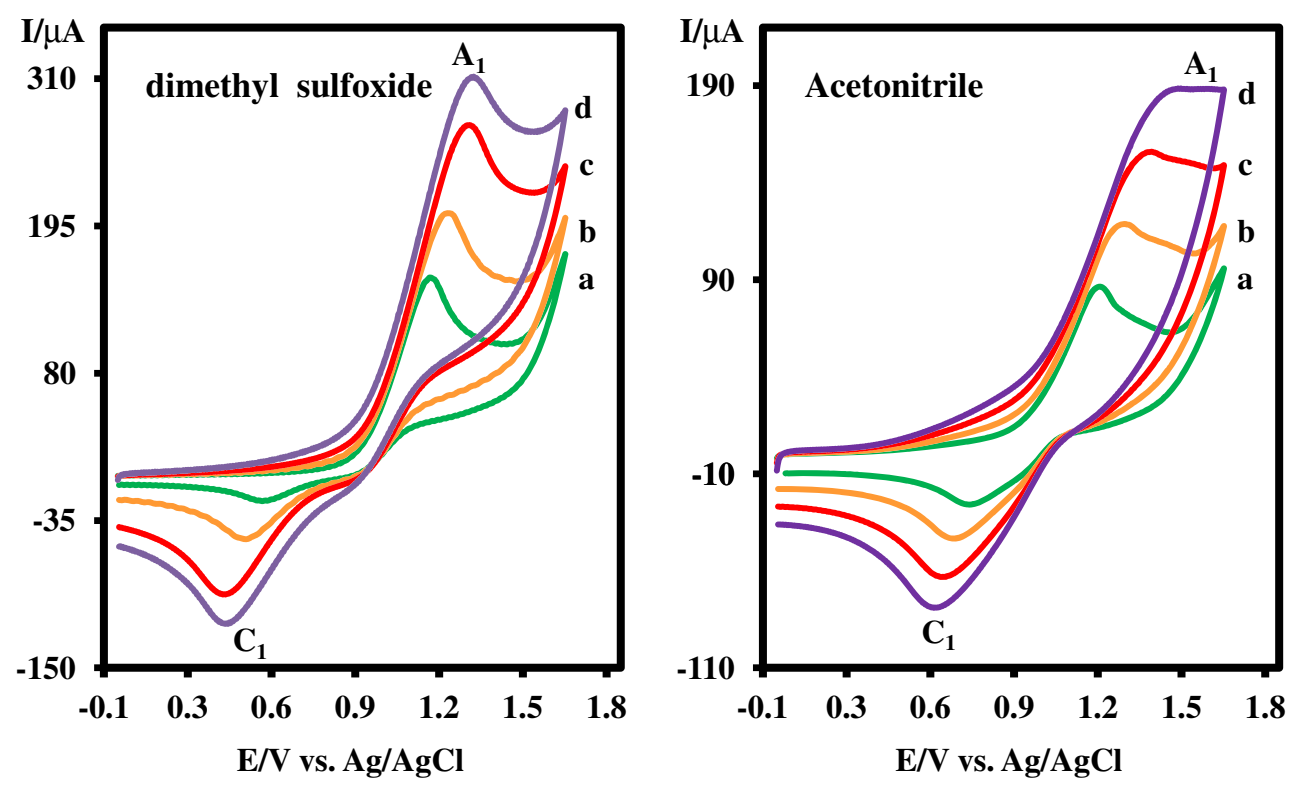

Figure 4. Cyclic voltammograms of $1.0 \mathrm{mM}$ of DHP at various scan rates in $0.1 \mathrm{M}$ tetrabutylammonium perchlorate, in DMSO and $\mathrm{AN}$, at a glassy carbon electrode. Scan rates from a to c are $100,200,400$ and $500 \mathrm{mV} / \mathrm{s} . T=25 \pm 1^{\circ} \mathrm{C}$.

\subsection{Electrochemical studies in non-aqueous solutions}

The oxidative ring cleavage (ORC) rates are dependent on the type of solvent. ${ }^{18,19}$ Therefore, the effect of some amphiprotic and aprotic solvents such as acetic acid, methanol, ethanol, acetonitrile and dimethylsulfoxide (DMSO) on the oxidative conversion of DHP has been examined. As shown in scheme 3, the rate of ORC is dependent on the autoprotolysis constant $\left(K_{\mathrm{SH}}\right)$ and basicity character of the solvent and it is expected that PTD would be unstable in amphiprotic solvents with high $K_{\mathrm{SH}}$ and basicity. The values of $\mathrm{p} K_{\mathrm{SH}}$ and basicity of the studied solvents are shown in table $1 .^{20}$

The cyclic voltammograms of DHP recorded in amphiprotic solvents; acetic acid, methanol and ethanol are shown in figure 3 . The cyclic voltammograms of DHP in methanol and ethanol displayed an irreversible feature due to the relatively high basicity and $K_{\mathrm{SH}}$ of these solvents. The basicity of these solvents is comparable with water (table 1). Unlike the methanol and ethanol, in acetic acid, the peak current ratio $\left(I_{\mathrm{pCl}} / I_{\mathrm{pAl}}\right)$ increases slightly upon increasing the potential scan rate. This confirms the relative stability of PTD in acetic acid due to the low basicity of acetic acid compared to water (table 1).

These experiments were repeated in aprotic solvents acetonitrile and DMSO (figure 4). The cyclic voltammograms of DHP in these solvents show one anodic peak $\left(\mathrm{A}_{1}\right)$ and the corresponding cathodic peak $\left(\mathrm{C}_{1}\right)$ which correspond to the transformation of DHP to PTD and vice versa within a quasi-reversible two-electron process. At these conditions, the peak current ratio $\left(I_{\mathrm{pC} 1} / I_{\mathrm{pA} 1}\right)$ at high potential scan rates is nearly unity. This can be considered as a criterion for the relative stability of PTD produced at the surface of the electrode under the experimental conditions. In other words, in the acetonitrile and DMSO, the rate of ORC is too low to be observed on the time scale of cyclic voltammetry. This finding is related to the very low $K_{\mathrm{SH}}$ of these solvents compared to amphiprotic solvents (table 1). In the case of DMSO as a solvent, although it is a basic solvent, but its autoprotolysis occurs slightly (table 1$){ }^{20}$ Thus, while the lyate ion of DMSO $\left(\mathrm{CH}_{3} \mathrm{SOCH}_{2}^{-}\right.$, dimsyl ion) is somewhat stable, its effect on the cyclic voltammograms of DHP is negligible due to very low $K_{\mathrm{SH}}$.

\section{Conclusions}

The results of this study support the previous reports on the anodic oxidation of 1,2-dihydropyridazine3,6-dione, ${ }^{16}$ and show that 2,3-dihydrophthalazine1,4-dione (DHP) is oxidized to phthalazine-1,4-dione (PTD). PTD is unstable and participates in a fast following chemical reaction (oxidative ring cleavage) to form phthalic acid. The reaction mechanism for the oxidative conversion of DHP is presented in scheme 3 . The rate of this reaction is dependent on the solvent autoprotolysis constant $\left(K_{\mathrm{SH}}\right)$ and basicity. Thus, PTD is unstable in non-aqueous amphiprotic solvents with high $K_{\mathrm{SH}}$, while PTD is more stable in aprotic solvents. 
Moreover, it was found that the $\mathrm{pH}$ dependence of DHP is about $55 \mathrm{mV} / \mathrm{pH}$, in the $\mathrm{pH}$ range from 1.0 to 5.3 and $33 \mathrm{mV} / \mathrm{pH}$, in the $\mathrm{pH}$ range from 5.3 to 9.0 .

\section{Acknowledgement}

We acknowledge Bu-Ali Sina University Research Council and Centre of Excellence in Development of Environmentally Friendly Methods for Chemical Synthesis (CEDEFMCS) for their support to carry out this work.

\section{References}

1. Lebsack A D, Gunzner J, Wang B, Pracitto R, Schaffhauser H, Santini A, Aiyar A, Bezverkov R, Munoz B, Liu W and Venkatraman S 2004 Bioorg. Med. Chem. Lett. 142463

2. Zhang L, Guan L, Sun X, Wei C, Chai K and Quan Z 2009 Chem. Biol. Drug. Des. 73313

3. Salvi V K, Bhambi D, Jat J L and Talesara G L 2006 ARKIVOC xiv 133

4. Ryu C, Park R, Ma M and Nho J 2007 Bioorg. Med. Chem. Lett. 172577

5. Deshpande S R, Ghongade A M and Pai V K 2010 Indian J. Pharm. Educ. Res. 441

6. Bedoya L M, Olmo E, Sancho R, Barboza B, Beltrán M, García-Cadenas A E, Sánchez-Palomino S, López-Pérez J L, Muñoz E, Feliciano A S and Alcamí J 2006 Bioorg. Med. Chem. Lett. 164075
7. Mey M V, Bommele K M, Boss H, Hatzelmann A, Slingerland M V, Sterk G J and Timmerman H 2003 J. Med. Chem. 462008

8. Yamaguchi M, Koga T, Kamei K, Akima M, Maruyama N, Kuroki T, Hamana M and Ohi N 1994 Chem. Pharm. Bull. 421850

9. Olmo E, Armas M G, López-Pérez J L, Muñoz V, Deharo E and Feliciano A S 2001 Bioorg. Med. Chem. Lett. 112123

10. Madhavan G R, Chakrabarti R, Kumar S K B, Misra P, Mamidi R N V S, Balraju V, Kasiram K, Babu R K, Suresh J, Lohray B B, Lohray V B, Iqbal J and Rajagopalan R 2001 Eur. J. Med. Chem. 36627

11. Merenyi G, Lind J and Eriken T E 1968 J. Am. Chem. Soc. 1087716

12. Kealy T 1962 J. Am. Chem. Soc. 84966

13. Lind J, Mereyi G and Eriksen T E $1983 \mathrm{~J}$. Am. Chem. Soc. $\mathbf{1 0 5} 7655$

14. Amarasekara A S and Chandrasekara S 2002 Org. Lett. 4773

15. Clement R 1962 J. Org. Chem. 271115

16. Varmaghani F and Nematollahi D 2013 Electrochim. Acta $\mathbf{5 6} 6089$

17. Mirahmadpour $P$, Nematollahi D, Davarani S S and Varmaghani F 2013 J. Electrochem. Soc. 160 G156

18. Jensen F and Foote C S 1987 Photochem. Photobiol. 46 325

19. Nematollahi D and Varmaghani F 2011 J. Iran. Chem. Soc. 8803

20. Izutsu K 2002 In Electrochemistry in Nonaqueous Solutions (Weinheim: Wiley-VCH) 